\title{
Bandeira de Santa Teresa Ecos da obra de Teresa de Ávila em nove poemas de Manuel Bandeira
}

\author{
Ana Ferreira
}

\section{Resumo}

O objetivo do presente artigo é apresentar a hipótese de diálogo da obra do poeta brasileiro Manuel Bandeira com a da santa poeta espanhola Teresa de Ávila. Considerando a colaboração de Manuel Bandeira na tradução da obra de Santa Teresa de Ávila para o português, e a simultaneidade do erótico e o místico recorrente nos versos bandeirianos, buscamos revelar possíveis ecos da obra desta importante expressão da poesia religiosa do Siglo de Oro espanhol em nove poemas de Bandeira, integrantes de livros vários: de Carnaval, publicado em 1919, a Opus 10, de 1952. Na breve análise destes nove poemas de Manuel Bandeira, destacamos possíveis influências da obra de Santa Teresa, na forma, nos termos, símbolos, e até na cronologia, tendo em conta ainda a biografia do poeta modernista. Além da influência literária propriamente dita, Teresa de Ávila parece se desdobrar em objeto de desejo do sujeito lírico, constando em versos ao longo de toda a obra de Bandeira, em disposição que sugere etapas de uma longa relação amorosa.

Palavras-chave: modernismo brasileiro; influências do Siglo de Oro; erotismo e misticismo na poesia; poesia erótica; poesia religiosa .

\section{Resumen}

El objetivo del presente artículo es presentar la hipótesis de diálogo de la obra del poeta brasileño Manuel Bandeira con la de la santa poeta española Teresa de Ávila. Considerando la colaboración de Manuel Bandeira en la traducción de la obra de Santa Teresa de Ávila al portugués, y la simultaneidad de lo erótico y lo místico en los versos bandeirianos, buscamos revelar posibles ecos de la obra de esta importante expresión del Siglo de Oro español en nueve poemas de Bandeira, integrantes de distintos libros: desde Carnaval, publicado en 1919, hasta Opus 10, de 1952. En el breve análisis de los nueve poemas de Manuel Bandeira destacamos posibles influencias de la obra de Santa Teresa en la forma, en los términos, los símbolos, y hasta en la cronología, teniendo en cuenta aún la biografía del poeta modernista. Más allá de la influencia literaria propiamente dicha, Teresa de Ávila parece desdoblarse en objeto de deseo del sujeto lírico, constando en los versos a lo largo de toda la obra de 
Bandera, en disposición que sugiere etapas de una larga relación amorosa.

Palabras clave: modernismo brasileño; influencias del Siglo de Oro; erotismo y misticismo en la poesía; poesía erótica; poesía religiosa

\section{O SEXO SOB O SACRO}

"O seu lirismo amoroso engloba o jogo erótico mais direto e, simultaneamente, as fugas mais intelectualizadas da louvação", são palavras de Antonio Candido e Gilda, no prefácio de Estrela da vida inteira, sobre os antagonismos na poesia de Manuel Bandeira, o "poeta sem Deus, que sabe não obstante falar tão bem de Deus e das coisas sagradas". (BANDEIRA, 2008, p. 3).

A não realização do amor, recorrente na obra de Manuel Bandeira, além de herança do trovadorismo, poderia ser relacionada à tuberculose descoberta aos dezessete anos, o que levaria o poeta a isolar-se, como é sabido. Bandeira nunca se casou e, embora declaradamente profano e enquadrado no zeitgeist moderno, acreditava na inspiração e valeu-se poeticamente de muitas imagens religiosas, em especial na sua lírica amorosa. Manuel Bandeira nunca se casou em vida, mas talvez tenha se casado em seus versos, depois de uma longa relação com a também poeta Santa Teresa de Ávila ${ }^{1}$, uma das maiores expressões da literatura religiosa do "Siglo de Oro" espanhol.

A simultaneidade do erótico e do místico presente na obra de Santa Teresa de Ávila é recorrente nos poemas de Manuel Bandeira, assim como a própria santa poeta que figura como amada, ora velada, ora declaradamente, o que buscamos demonstrar em dez poemas: A relação parece começar em "Toante", "Sonho de uma terça-feira Gorda" e "A fina, a doce ferida"; há um possível rompimento em "Oração a Teresinha do Menino Jesus" e "Teresa"; um reencontro em "Oração a Santa Teresa" e "No vosso e em meu coração"; o ápice se dá em "Unidade", ao que nos detemos, se completa em "Arte de amar"; e, finalmente, "Cântico dos Cânticos" seria o casamento lírico com a santa extática.

Ainda, lembrando que o cotidiano é matéria dos poemas bandeirianos, Santa Teresa dá nome ao bairro carioca em que Bandeira morou durante treze anos, na rua do Curvelo, próximo ao convento das Carmelitas Descalças, onde se daria a tradução da obra de Teresa de Ávila para o português, coordenada pela monja Madre Maria José de Castro, com quem Bandeira trava uma amizade intelectual ${ }^{2}$, e colabora na tradução da obra poética ${ }^{3}$. Segundo a tese de Virgínia Albuquerque de Castro Buarque, Madre Maria José de Jesus dedicou duas décadas à tradução da Obra Completa de Santa Teresa, iniciada em 1935, e a tradução da obraprima, Castelo Interior ou Moradas, foi publicada em $1946^{4}$.

\section{Santa Teresa em dez poemas de Manuel Bandeira}


A coletânea Carnaval, de 1919, conta com diversas alusões e expressas menções à Teresa de Ávila, ou Teresa de Jesus, como era conhecida em vida e como foi citada no poema "Toante". ${ }^{5}$
Foi assim que Teresa de Jesus amou...
Molha em teu pranto de aurora as minhas mãos pálidas
O espasmo é como um êxtase religioso...
E o teu amor tem o sabor de tuas lágrimas...

Nesta coletânea, o poema "Toante" é sucedido pelo muito estudado "Alumbramento", e depois vem "Sonho de uma terça-feira Gorda" , que também evoca Santa Teresa.

\footnotetext{
Tão contrastado pelo sentimento de felicidade

Que nos penetrava. Um lento, suave júbilo

Que nos penetrava... Que nos penetrava como uma espada de fogo...

Como a espada de fogo que apunhalava as santas extáticas.
}

Sendo o discurso erótico caracterizado por apresentar termos referentes ao sexo, Manuel Bandeira o realiza com moderação, recorrendo à metáfora em alusões às zonas mais íntimas ${ }^{8}$. Em "Toante", o objeto de desejo parece ser Teresa de Ávila, que aparece pluralizada em "santas extáticas", entre outras ocorrências, como o verbo "penetrava" e a comparação à "espada de fogo", referentes ao sexo. Ainda no livro Carnaval, o poema "A fina, a doce ferida" parece referir-se à transverberação divina relatada pela santa escritora, hipótese que se ancora nos oxímoros "doce ferida", "dor do meu gozo", e ainda no termo "quebranto", que é a indolência advinda da fraqueza e do abatimento, mas também significa transgressão, infração:
A fina, a doce ferida
Que foi a dor do meu gozo
Deixou quebranto amoroso
$\mathrm{Na}$ cicatriz dolorida.

Já no livro Libertinagem, publicado em 1930, "Teresa"10 dá nome a um poema, em que o sujeito lírico relata as impressões em três vezes que a viu. Neste poema, "Teresa" parece humana em distintas fases da vida, dividida em três estrofes: na primeira vez, as "pernas estúpidas" e "a cara que parecia uma perna" sugerem um bebê; quando o sujeito lírico vê Teresa "de novo", "os olhos eram muito mais velhos que o resto do corpo" com distância cronológica de dez anos; "Da terceira vez", diz o poeta na última estrofe, marcando preposicionalmente não um lugar ou ocasião, mas a permanência, pois desde então a humana Teresa, possivelmente já mulher, parece lhe cegar numa epifania:

Da terceira vez não vi mais nada

Os céus se misturaram com a terra 
Nos versos de finais de "Teresa", terreno e celestial se misturam, talvez mesclando também a Teresa humana com a santa, ou a projetando nesta, elevando-a, afinal. No entanto, pouco adiante neste mesmo livro, o sujeito lírico parece negar a atormentada Santa Teresa, preferindo a singela homônima nos versos do poema "Oração a Teresinha do Menino Jesus"11:

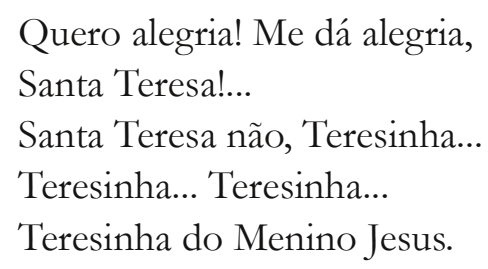

Ainda neste livro, depois de negar a santa extática espanhola, o sujeito lírico parece resgatar a "Teresa" supostamente humana do poema com seu nome; depois de um elogio pueril, vem a comparação ao animal de estimação da infância que figura no brevíssimo "Madrigal tão engraçadinho"12. Este poema naturalmente dialoga com o "Porquinho-daÍndia", também integrante de Libertinagem, donde se deduz que a comparação de Teresa ao animal se deve ao comportamento semelhante, ou seja, uma Teresa fugidia como o "porquinho-da-Índia” que fugia para "debaixo do fogão!", ao que o poeta confessa no último verso, num alumbramento com ênfase gráfica: “ - O meu porquinho-da-Índia foi minha primeira namorada." 13 .

Curiosamente, no livro Mafuá do Malungo, impresso na Espanha (por João Cabral de Melo Neto), em 1948, a santa espanhola negada em Libertinagem é então exaltada repetidas vezes no poema "Oração a Santa Teresa" ${ }^{14}$, que percorre o bairro em que vivera o poeta e que leva o nome dela.

\section{Santa Teresa olhai por nós \\ Moradores de Santa Teresa \\ Santa Teresa olhai por nós \\ Moradores de Santa Teresa}

No livro Belo belo, também de 1948, o poema "No vosso e em meu coração"15 exalta a "Espanha da liberdade" e nega a "Espanha da opressão", "da Inquisição"; "A Espanha de Franco, não!”, exclama o sujeito lírico reiteradamente. Personalidades históricas de distintas épocas figuram nos versos, vituperados ou aclamados. Também artistas e poetas antigos e contemporâneos são exaltados, e Teresa de Ávila aparece entre os representantes da poesia religiosa do Siglo de Oro espanhol ${ }^{16}$ :

Espanha dos grandes místicos, 

Dos santos poetas, de João
Da Cruz, de Teresa de Ávila
E de Frei Luís de Leão!
Espanha da livre crença,
Jamais a da Inquisição!

Também integrante da coletânea Belo belo, é o poema "Unidade"17, ponto de partida deste estudo, e ápice da relação do moderno poeta brasileiro com a santa espanhola do Siglo de Oro.

"Unidade", de Manuel Bandeira, é um poema de alto teor erótico e místico, composto em versos livres e irregulares, sendo que apenas o dístico inicial apresenta regularidade, composto em versos de nove sílabas poéticas, medida que se repete no último verso de cada estrofe. A divisão das estrofes marca tempos, imagens e ações distintas, que seguem num crescendo, em cadência peculiar, fundindo contrastes na conclusão. A primeira estrofe é um dístico regular, forma que lembra o "cabeçalho" frequente nos poemas de Teresa de Ávila ${ }^{18}$, entre outros poetas do século que produziam poemas a partir de glosas, como se observa em "Buscando a Dios"19, iniciado em dístico, qual o poema "Unidade" não por acaso.

Alma, buscarte has en Mí, y a Mí buscarme has en ti.

No poema "Unidade" o paralelismo entre corpo e alma se estabelece já no início do primeiro verso, na contração "Minh'alma", e a distância desta "naquele instante" aponta para a epifania, o alumbramento ${ }^{20}$.

\section{Minh'alma estava naquele instante \\ Fora de mim longe muito longe}

O segundo verso a reafirma e intensifica na recorrência "longe muito longe", cuja sonoridade sugere um eco, assim como anuncia o ritmo sensual que se desenvolverá ao longo do poema, visto que muda tudo, clima, tempo, cenário, som, ritmo, imagens e, sobretudo, o eu-poético, voltado à segunda pessoa, que surge majestática, sendo o verso inaugural da sextilha preenchido unicamente com o verbo "Chegaste".

\section{Chegaste}

E desde logo foi verão

O verão com as suas palmas os seus mormaços os seus ventos de sôfrega mocidade

Considerando que a unidade rítmica do verso é função do significado traduzido em imagens apropriadas ${ }^{21}$, o encontro amoroso é metaforizado na estação Verão e em seus predicados; as imagens que ilustram o "verão" são típicas do litoral tropical e dotadas de ambiguidade: o termo "palmas" faz menção à vegetação dos trópicos, uma imagem um tanto 
fálica, mas também seria a palma benta distribuída em celebrações cristãs, como o Domingo de Ramos que abre a Semana Santa; o termo "mormaços" é ainda mais ambíguo, diz respeito ao clima tropical úmido, além de metáfora de dúvida e sinônimo de namoro no vocabulário pernambucano. Depois dos "mormaços" abafados, vêm os "ventos" afobados, e o calor se intensifica na recorrência de "verão" no quinto verso, o mais extenso e ávido do poema. Composto de vinte e quatro sílabas poéticas, o quinto longo verso ocorre quase que numa progressão geométrica em relação aos dois anteriores, sendo o terceiro verso composto em duas sílabas poéticas, e o quarto em oito. A progressão dos três versos sugere um entusiasmo crescente, e a cadeia de imagens sem qualquer pontuação exprime o clima febril do desejo erótico, assim como o ritmo regular produzido pela recorrência "os seus" - com uma variação no feminino - sugere os batimentos cardíacos e a respiração ofegante, e quase falta fôlego ao final do sôfrego verso.

Nos versos seguintes, o erotismo manifesta-se em termos expressos, engendrando um vão embate entre o afeto indolente e o instinto animal.

A não realização do amor, recorrente na obra de Manuel Bandeira, embora frequentemente associada à tuberculose que levou o poeta a isolar-se ${ }^{22}$, mais parece ser herança do trovadorismo.

\footnotetext{
Debalde os teus afagos insinuavam quebranto e molície

O instinto de penetração já despertado

Era como uma seta de fogo
}

Anteriormente utilizado por Bandeira, no poema "A fina, a doce ferida", conforme apontamos, o vocábulo "quebranto" é resgatado em "Unidade", reiterando sua associação à Teresa, que para atingir êxtases espirituais, submetia-se a prolongados jejuns. De mesma forma, o verbo "insinuavam" tem o sentido de persuasão, de "dar a entender algo com sutileza", ao mesmo tempo em que quer dizer "introduzir, fazer penetrar no ânimo, no coração", literalmente como seria uma transverberação divina. Nos versos seguintes, o erotismo latente declara-se plenamente na comparação do "instinto de penetração" a "uma seta de fogo", e chegamos ao ápice do poema, ao momento lírico da penetração, ou da transverberação, visto que "seta de fogo" é o símbolo ${ }^{23}$ religioso atribuído à Santa Teresa de Ávila, "como a grelha de São Lourenço e a roda de Santa Catarina"24. Assim, no poema "Unidade", Manuel Bandeira parece fazer a inversão do êxtase espiritual descrito pela santapoeta na obra Castelo Interior ou Moradas, valendo-se exatamente da comparação a uma "seta de fogo":

“andándose así esta alma, abrasándose en sí misma, acaece muchas veces por un pensamiento muy ligero, o por una palabra que oye de que se tarda el morir, venir de otra parte -no se entiende de dónde ni cómo- un golpe, o como si viniese una seta de fuego." 25 
Em Castelo Interior on Moradas, Teresa de Ávila narra a sucessão de estágios que a alma percorre rumo a Deus, e no poema "Unidade", de Manuel Bandeira, depois da possível inversão de êxtase espiritual em orgástico, o retorno da alma ao corpo conotado decorre de forma gradativa e com ritmo fluente, ressurge a contração "minh'alma" que iniciou o poema e ausente esteve desde então.

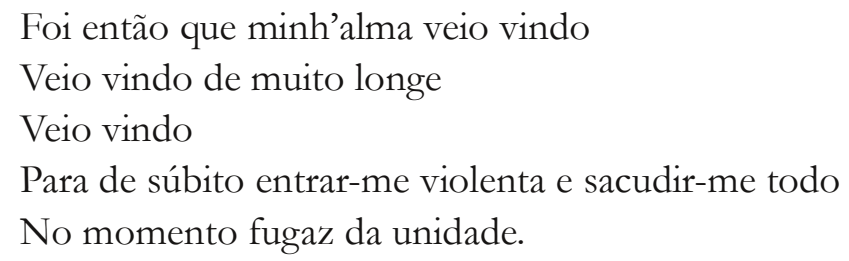

O retorno da alma ao corpo conotado decorre de forma gradativa e com ritmo fluente, em tempo verbal composto "veio vindo", em anáfora. A homofonia absoluta produzida pela repetição "veio vindo", em três versos sequentes, marca a cadência rítmica fluente, fortalecendo o caráter erótico; o movimento de vai e vem do ato sexual, nesta estrofe configura-se "veio vindo", e nos dois versos finais, ocorre a fusão do corpo e da alma ${ }^{26}$, havendo uma brusca mudança rítmica, sonora e semântica, no penúltimo verso. É o êxtase sexual que vem com força impetuosa e intempestiva, "de súbito". A acentuação da vogal "u" reforça a "violenta" entrada da alma, de repente, num golpe de amor. Neste verso, há pleno domínio do presente imediato, expresso em ênclise nos verbos "entrar-me", "sacudir-me", sendo a sonoridade realizada aos trancos. É o orgasmo que faz o corpo "todo" estremecer, agitando-se fortemente repetidas vezes. O adjetivo "todo" é completude total, nada fica de fora; corpo e alma se unem num átimo, em síntese dialética, sendo "unidade" o termo final, que dá título ao poema.

$\mathrm{Na}$ linguagem científica, "unidade" é aquilo que não pode ser dividido, é a unicidade, a totalidade, a completude. Neste poema de Manuel Bandeira, "unidade" é metáfora de um grande orgasmo, do gozo carnal arrebatador, quando corpo e alma se unem num átimo, em síntese dialética que termina com o ponto final.

E se "alma" é a segunda palavra mais empregada nos poemas bandeirianos ${ }^{27}$, no livro Belo belo, o poema seguinte ao "Unidade" é "Arte de amar"28, e curiosamente, Manuel Bandeira irá negar a unicidade, cindindo corpo e alma, definitivamente.

Se queres sentir a felicidade de amar, esquece a tua alma.

A alma é que estraga o amor.

Só em Deus ela pode encontrar satisfação.

Não noutra alma.

Só em Deus - ou fora do mundo.

As almas são incomunicáveis. 
Porque os corpos se entendem, mas as almas não.

Em "Arte de amar", o corpo se liberta da alma, a volúpia sexual se exime do amor espiritual; em palavras de Davi Arrigucci, "como uma perturbação do espírito, súbita inclinação da alma, ou seja, uma emoção agitada por um movimento sem direção, sugerindo por vezes imagens de tempestade." (1990: p. 82).

Posteriormente ao livro Belo belo, há outra provável alusão à Teresa de Ávila, no poema "Cântico dos Cânticos"29, integrante da coletânea Opus 10, publicada em 1952. O poema, composto em forma de diálogo - entre um casal de amantes -, é inspirado no livro bíblico homônimo, escrito pelo rei Salomão, sendo este mais um ponto de contato da obra de Bandeira com a de Teresa de Ávila, que escreveu a polêmica obra conhecida como Meditaciones sobre Cantares, a qual ela própria teria queimado por ordem de seu confessor, porém, salvaramse "algumas cópias que circulavam pelo convento" 30 . A obra consta de meditações de Teresa sobre alguns versículos de Cântico dos Cânticos, ou Cantares de Salomão, tendo recaído a escolha da autora sobre os trechos de maior erotismo ${ }^{31}$. Igualmente o faz Manuel Bandeira no poema "Cântico dos Cânticos" 32 , em que o livro bíblico fonte é a aliança, e os versos o casamento do sujeito lírico com Santa Teresa de Ávila. A provável evocação apresenta-se em diversos termos, a começar por "dardo", no sexto verso:

Meu calor, meu túrgido dardo.

Além de "seta de fogo" e "espada", a transverberação divina é descrita por Teresa de Ávila como um "dardo", no Livro da Vida $a^{33}$. E no oitavo verso de "Cântico dos Cânticos", Bandeira utiliza o termo "golpes", que também é uma descrição de transverberação bastante usada por Teresa ${ }^{34}$; a maiúscula em "Amor" faz referência ao divino.

- Quando por mais assegurada

Contra os golpes de Amor me tinha,

Eis que irrompes por mim deiscente...

No nono verso, "irrompes" indica uma entrada impetuosa e violenta; e "deiscente" diz respeito a fruto, mas é também a abertura de uma ferida. E a sugestão à chaga da transverberação divina se reforça com o termo "Púrpura" no verso seguinte.

- Cântico! Púrpura! Alvorada!

Os três versos finais oferecem fortes indícios de que a "noiva" apresentada por Bandeira seja inspirada em Teresa de Ávila. 
Além de "me entras profundamente" sugerir transverberação, a comparação "Como um deus em sua morada" parece evocar a obra Castelo Interior on Moradas, de Teresa de Ávila, porém há generalização em "um deus", que não é particularizado por maiúscula como em "Amor". E o último verso do poema é a resposta a estes versos.

- Como a espada em sua bainha.

Mais que resposta, o verso final tanto retifica como complementa o verso anterior, valendo-se de outra comparação, "Como a espada", que sugere a transverberação, porém com recusa, sem dor nem ferimento, sem golpe nem ferida, o amor enfim em paz, colocando a espada "em sua bainha", um encaixe perfeito como uma aliança no dedo, como o pênis na vagina; e o artigo definido particulariza "a espada". "Cântico dos cânticos" parece o casamento do sujeito lírico com a santa evocada nos versos da vida inteira de Manuel Bandeira.

\section{CONSIDERAÇÕES FINAIS}

Conforme expõe Costa Santos em sua tese, "a poesia de Manuel Bandeira está povoada de santas", dentre as quais, Virgem Maria é a mais recorrente ${ }^{35}$. Seja em tom reverente ou irônico, o sagrado permeia a obra de Bandeira; velada ou declaradamente, o poeta convoca, invoca ou se lamenta a Santa Rosa, Santa Clara, Santa Rita dos Impossíveis, Santa Maria Egipcíaca, Nossa Senhora da Boa Morte, Nossa Senhora de Nazareth, Santa Teresinha do Menino Jesus, e Santa Teresa de Ávila, entre outros santos e anjos, almas, cruzes, estrelas e rosas simbólicas ${ }^{36}$.

Ainda que permeie a obra de Manuel Bandeira, a ocultação do erotismo em imagens sacras é uma face carente de investigação ${ }^{37}$, sobretudo o provável diálogo com a obra de Santa Teresa de Ávila, que parece muito recorrente em sua poesia, como buscamos demonstrar nestes dez poemas de Bandeira, com ênfase em "Unidade". Desta forma, reiterando a hipótese de evocação à Santa Teresa apresentada na análise dos poemas, vale lembrar que nosso "São João Batista do Modernismo", além de beber na fonte do Simbolismo, acompanhou a tradução da obra de Teresa de Ávila, feita por Madre Maria José de Jesus, a quem teria dado orientações, como se constata na tese de Virgínia Albuquerque de Castro Buarque ${ }^{38}$, e a quem admirava como poeta ${ }^{39}$.

Santa Teresa fazia parte do dia a dia do poeta Manuel Bandeira; inspiradora, perturbadora ou abstraída, lá estava ela nas alturas do bairro, nas conversas e colaboração à amiga monja que a traduz, e nos seus versos, por fim. 


\section{NOTAS}

1. Teresa de Ahumada Sanchez y Cepeda, Ávila, Espanha, (1515-1582).

2. "este proceso de recuperación de un género literario en riesgo de olvido se repetiría en Brasil en los años cincuenta, cuando Manuel Bandeira, al igual que Valery, se dedicó a la tarea de promover la desconocida obra de la Madre Maria José. Bandeira y la madre desarrollaron una curiosa amistad intelectual." AYRES, 1992. p.256.

3. "este proceso de recuperación de un género literario en riesgo de olvido se repetiría en Brasil en los años cincuenta, cuando Manuel Bandeira, al igual que Valery, se dedicó a la tarea de promover la desconocida obra de la Madre Maria José. Bandeira y la madre desarrollaron una curiosa amistad intelectual." AYRES, 1992. p.256.

4. BUARQUE, Virgínia Albuquerque de Castro. Mistica em tempos de neocristandade: as cartas de uma monja Carmelita Descalça no Brasil. UFRJ, 2007.

5. BANDEIRA, 2008, p.98.

6. BANDEIRA, 2008, p.99.

7. BANDEIRA, 2008, p.98.

8. "O discurso erótico tem como característica trazer vocábulos que estão relacionados à genitália e ao ato sexual. [...] quando deseja lembrar as partes mais íntimas, [Manuel Bandeira] recorre à metáfora." LUCENA JUNIOR, J. F. Discurso erótico em três poetas modernistas: Manuel Bandeira, Carlos Drummond de Andrade e João Cabral de Melo Neto, 2009. p. 27.

9. BANDEIRA, 2008, p.87.

10. BANDEIRA, 2008, p.136.

11. BANDEIRA, 2008, p.138.

12. "Teresa você é a coisa mais bonita que eu vi até hoje na minha vida, inclusive o porquinhoda-Índia que me deram quando eu tinha seis anos.". Poema "Madrigal tão engraçadinho", de Manuel Bandeira, livro Libertinagem, In. BANDEIRA, 2008, p.140.

13. BANDEIRA, 2008, p.130.

14. BANDEIRA, 2008, p.304.

15. BANDEIRA, 2008, p.196.

16. "Valéry y Bandeira, como poetas y criticos, encontraron en el Siglo de Oro español y en las figuras oscuras de dos religiosos y traductores materia de reflexión sobre la naturaleza misma del proceso de renovación de la poesía”. AYRES, 1992, p.257. 
18. GUTIÉRREZ, Jorge Luis. "Teresa de Ávila: a poesia como colóquio amoroso com Deus". Revista Pandora Brasil - ISSN 2175-3318 - Março, 2010.

19. ÁVILA, 1995, p.978.

20. "O verso livre dos simbolistas, frequentemente "verso libertado", sofre novas transformações e o metro cede lugar ao ritmo [...] E como o verso não é só unidade sonora e musical, mas também uma unidade significativa, carece de outros elementos para reforçar o seu caráter poético, os quais são as unidades expressivas: imagem, metáfora, figuras, símbolos, alegorias." CANDIDO, A. - O estudo analítico do poema. p.92.

21. “a analogia está na base da linguagem poética, pela sua função de vincular opostos, as coisas diferentes, e refazer o mundo pela imagem. Por essa razão a unidade do verso é função do significado (...), mas de um significado traduzido em imagens apropriadas." CANDIDO, A. - O estudo analítico do poema. p. 108.

22. "A oposição entre uma natureza apaixonada que aspirava à plenitude e o exílio em que a doença o obrigará a viver, marcará profundamente a sua sensibilidade, traduzindo-se, no plano estrutural, pelo gosto das antíteses, dos paradoxos, dos contrastes violentos; no plano emocional, por um movimento polar, uma oscilação constante que, no decorrer da obra, vai alterar a atitude de serenidade melancólica e o sentimento de revolta impotente." BANDEIRA, Manuel. Estrela da Vida Inteira - prefácio de Antonio Candido e Gilda, p. 12.

23. "A promover a atribuição simbólica está, portanto, uma certa concordância, uma analogia esquemática, uma relação essencial.” ECO, H. Arte e beleza na estética medieval. p. 108.

24. "A cruz não é uma metáfora, mas sim um símbolo metafórico, representando Aquele que morreu nela, como a grelha de São Lourenço e a roda de Santa Catarina, ou representando o sofrimento, caso em que o instrumento significa aquilo que faz, o efeito da sua ação. [...] Os "símbolos" algébricos e lógicos são signos convencionais; mas os símbolos religiosos baseiamse nalguma relação intrínseca entre o "signo" e a coisa "significada" - relação metonímica ou metafórica: a Cruz, o Cordeiro, o Bom Pastor.” WELLEK, René; e WARREN, Austin. Teoria da Literatura. p. 237 - 256.

\section{5. ÁVILA, T. Castelo Interior ou Moradas, cap.11.}

26. "É graças a esta confiança na sabedoria do instinto que se forma o sentimento da transcendência, manifestada como imanente aos versos naturais. No poema "Unidade"(...) a alma se revela como consequência de tais gestos, parecendo nascer deles. E o leitor, ao mesmo tempo que se vê mergulhado nos aspectos fenométricos, sente-se arrebatado para as mais altas abstrações.” BANDEIRA, M. Estrela da Vida Inteira. Antonio Candido e Gilda - p. 4.

27. Segundo levantamento realizado por Luci Mary Melo Leon, “alma” é a segunda palavra mais empregada nos poemas bandeirianos, somando 80 ocorrências, sendo "vida" a primeira. LEON, Luci Mary Melo. Contribuições para organização de um glossário nominal da poesia de Manuel 
Bandeira. Tese de Doutorado, UERJ, 2007, p. 62.

28. BANDEIRA, 2008, p.206.

29. BANDEIRA, M. Estrela da Vida Inteira. p. 223.

30. GUTIÉRREZ, Jorge Luis. "A Filosofia Mística de Teresa de Ávila". Revista Caminhando, vol. 8 , n. 1 (11), 2003.

31. GUTIÉRREZ, Jorge Luis. "Teresa de Ávila: a poesia como colóquio amoroso com Deus." Revista Pandora Brasil - ISSN 2175-3318 - Março, 2010.

32. BANDEIRA, 2008, p.223.

33. "Veíale en las manos un dardo de oro largo, y al fin del hierro me parecía tener un poco de fuego. Este me parecía meter por el corazón algunas veces y que me llegaba a las entrañas. Al sacarle, me parecía las llevaba consigo, y me dejaba toda abrasada en amor grande de Dios." ÁVILA. Libro de la Vida. cap. 29, v 13.

34. "venir de otra parte - no se entiende de dónde ni cómo - un golpe" ÁVILA, T. Castelo Interior ou Moradas, cap.11.

35. COSTA SANTOS, João Eustáquio da. No fundo das minhas volúpias, Deus: A tensão entre o sagrado e o profano na poesia de Manuel Bandeira. Tese de Mestrado, UFMG, 2007. p. 80.

36. "Na visão simbólica, a natureza, até em seus aspectos mais temíveis, torna-se o alfabeto com o qual o criador nos fala da ordem do mundo, dos bens sobrenaturais, dos passos a serem dados para nos orientar ordenadamente no mundo, a fim de adquirir os prêmios celestes." ECO, Umberto. Arte e Beleza na Estética Medieval. Editora Record, Rio de Janeiro, 2010. p. 106.

37. "Embora não sejam poucas, por outro lado, as alusões a um possível, conforme Antonio Candido, "mal-estar espiritual" na poesia bandeiriana, que se desdobra numa forma irônica e irreverentemente corrosiva de se apropriar literariamente das imagens da religião cristã, não há estudos que tenham investigado, especificamente, essa recorrência ao longo de sua obra poética." COSTA SANTOS, J.E. No fundo das minhas volúpias, Deus: A tensão entre o sagrado e o profano na poesia de Manuel Bandeira. UFMG, 2007. p. 9.

38. "Quando as monjas do Carmelo faziam a tradução das Obras Completas de Santa Teresa, fui muitas vezes, a convite de minha prima [Irmã Maria do Carmo de Cristo Rei] ao locutório do Convento para conversar com ela e com Madre Maria José sobre dúvidas que elas tinham a respeito da nova ortografia". BANDEIRA, Manuel - "Uma Santa". Diário do Comércio, 18 mar. 1959. Cf. Artigos publicados sobre Madre Maria José de Jesus em Jornais, Revistas e Livros. In: Causa Canonizationis Servae Dei Maria e Ioseph a Iesu, ocd. V. 15. p.5. Citado em Mística em tempos de neocristandade: as cartas de uma monja Carmelita Descalca no Brasil. BUARQUE, Virgínia Albuquerque de Castro. UFRJ, 2007. 
39. "Madre Maria Jose de Jesus, religiosa carmelita, poeta y traductora de la obra de Santa Teresa de Avila al portugués (...), había establecido una rara colaboración literaria con el poeta Manuel Bandeira que le prologó el primer libro de poemas, publicado póstumamente (...) escribió Bandeira: "Madre Maria José escrevia versos no mesmo espírito em que os escrevera a grande santa Teresa de Avila" (Andorinha 292)." AYRES, Miriam. "Reflexos de la mística del siglo de oro español en El Brasil moderno: una lectura de la poesía de Madre Maria José de Jesus”. New York University, 1992. Revista Iberoamericana, vol. LXIV, n. 182-183. p.255. 
ARRIGUCCI JR., D. Humildade, paixão e morte: a poesia de Manuel Bandeira. São Paulo, Companhia das Letras, 1990.

ÁVILA, Teresa de. Obras Completas. Madrid, Biblioteca de Autores Cristianos, 2006.

Obras Completas - Teresa de Jesus (texto estabelecido por Fr Tomas Alvarez). S. Paulo, Edições Loyola, 1995.

Obras Completas. S. Paulo, Edições Loyola, 2002.

AYRES, M. "Reflexos de la mística del siglo de oro español em El Brasil moderno: uma lectura de la poesia de Madre Maria José de Jesus." Revista Iberoamericana, vol. LXIV, n. 182-183 - New York University, 1992.

BANDEIRA, M. Estrela da Vida Inteira. Rio de Janeiro, Editora Nova Fronteira, 2008.

Estrela da Vida Inteira. Rio de Janeiro, Editora José Olympio, 1974.

Antologia Poética. Rio de Janeiro, Editora Nova Fronteira, 2010.

Poemas religiosos e alguns libertinos. São Paulo, Cosac Naify, 2007.

BONNICI, T. e ZOLIN, L. O. Teoria Literária - abordagens históricas e tendências contemporâneas. UEM Maringá, 2009.

BOSI, Al. O Ser e o Tempo da Poesia. São Paulo, Editora Cultrix, 1983.

BUARQUE, V. A. C. Mística em tempos de neocristandade: as cartas de uma monja Carmelita Descalca no Brasil. UFRJ, 2007.
CANDIDO, A. O estudo analítico do poema. São Paulo: Humanitas, FFLCH, 2009.

Na sala de aula - caderno de análise literária. São Paulo: Editora Ática, 1986.

COSTA SANTOS, J. E. No fundo das minhas volúpias, Deus: A tensão entre o sagrado e o profano na poesia de Manuel Bandeira. UFMG, 2007.

ECO, U. Arte e Beleza na Estética Medieval. Rio de Janeiro: Editora Record, 2010.

Viagem na Irrealidade Cotidiana. Rio de Janeiro: Editora Nova Fronteira, 1984.

FERREIRA, Aurélio Buarque de Holanda. Novo Dicionário Aurélio da Lingua Portuguesa. Editora Positivo, 2004.

GUTIÉRreZ, J. L. A "Filosofia Mística de Teresa de Ávila". In: Revista Caminhando, vol. 8, n. 1 (11), 2003.

"Teresa de Ávila: a poesia como colóquio amoroso com Deus". In: Revista Pandora Brasil - ISSN 2175-3318 - Março, 2010.

HOUAISS, A. Dicionário Honaiss da Lingua Portuguesa. Rio de Janeiro, Editora Objetiva, 2007.

JACOBSON, R. Linguística e Comunicação. São Paulo: Cultrix, $2^{\mathrm{a}}$ edição.

KAYSER, W. Análise e interpretação da obra literária - I e II. Arménio Amado Editor, 1976.

LEON, L. M. M. Contribuições para organização de um glossário nominal da poesia de Manuel Bandeira. Tese de Doutorado, UERJ, 2007.

LUCENA JUNIOR, Jose Ferreira de - 
Discurso erótico em três poetas modernistas: Manuel Bandeira, Carlos Drummond de Andrade e João Cabral de Melo Neto, (catálogo USP), 2009.

ORDEM ROSACRUZ - AMORC. Ano MCML XXXII. Introducão à Simbologia. Grande Loja do Brasil, Curitiba, 1992.

PAZ, Octavio. Signos em Rotação. São Paulo, Editora Perspectiva, 2003.

ROSENFELD, A. O Teatro Épico. São Paulo Editora, Coleção Buriti, 1965
Texto/Contexto II. Editora Perspectiva, 1993.

STRAUSZ, R. A. Teresa - a santa apaixonada. Rio de Janeiro, Editora Objetiva, 2004.

WELLEK, R. e WARREN, A. Teoria da Literatura. Lisboa, Publicações Europa América, tradução José Palla e Carmo, 1971. 